\title{
IS EPISTEMIC SAFETY THREATENED BY FRANKFURT CASES? A REPLY TO KeLP
}

\author{
- Domingos Faria -
}

\begin{abstract}
I intend to argue that the counterexamples inspired by the Frankfurt-type cases against the necessity of an epistemic safety condition for knowledge are not plausible. The epistemic safety condition for knowledge is a modal condition recently supported by Sosa (2007) and Pritchard (2015), among others, and can be formulated as follows: (SC) If $S$ knows that $\mathrm{p}$ on basis B, then $\mathrm{S}^{\prime}$ s true belief that $\mathrm{p}$ could not have easily been false on basis B. I will try to argue that the safety condition, expressed in (SC), is still necessary for knowledge and that, therefore, epistemic safety is not threatened by Frankfurt type cases. In particular, I want to show that Kelp's counterexamples are ineffective against (SC). Keywords: knowledge, epistemic safety condition, Gettier, Frankfurt-type cases, Christoph Kelp.
\end{abstract} Published online: 10 April 2020

\section{Introduction}

In this paper, I intend to argue that the counterexamples inspired by the Frankfurt-type cases against the necessity of an epistemic safety condition for knowledge are not plausible. In order to defend this conclusion, I begin by analyzing what constitutes the epistemic safety condition.

The epistemic safety condition for knowledge is a modal condition recently supported by Pritchard ${ }^{1}$ and discussed by Sosa ${ }^{2}$, among others, and can be formulated as follows:

(SC) If $S$ knows that $\mathrm{p}$ on basis $\mathrm{B}$, then $\mathrm{S}^{\prime} \mathrm{s}$ true belief that $\mathrm{p}$ could not have easily been false on basis $B$.

In other words, the safety condition expressed in (SC) says that, in cases of knowledge, $S^{\prime}$ s true belief that $\mathrm{p}$ on basis B is such that, in close possible worlds (i.e. in very similar circumstances), if $\mathrm{S}$ continues to hold $\mathrm{p}$ on the same basis $\mathrm{B}$ as he does in the actual world, then $S^{\prime}$ s belief that $p$ continues to be true.

\footnotetext{
Domingos Faria

Centro de Filosofia da Universidade de Lisboa

Alameda da Universidade

1600-214 Lisboa

Portugal

df@domingosfaria.net

1 Pritchard (2015).

2 Sosa (2007).
} 
There are several advantages in adopting (SC), such as the fact that it can deal with the Gettier cases (at least typical ones), since in almost all of them the subject comes to hold a true belief in such a way that it could have very easily been false. ${ }^{3}$ For example, suppose Mary comes down the stairs in the morning to have breakfast, and when she looks at her normally reliable clock in the kitchen, it's 8:20 am. Additionally, suppose this belief is true and that it is in fact 8:20 am. Here we have a case in which Mary forms a true belief that seems to be the result of a reliable process. ${ }^{4}$

However, suppose that the clock actually stopped 24 hours ago, and it is just a matter of luck that Mary looks at the clock precisely at the only time of the day when it shows the correct time. In this case, even though Mary has good evidence or justification to believe that it is 8:20 am and her belief is true, she does not know that it is 8:20 am, since her belief is true merely by luck.

Now, the safety condition expressed in (SC) may explain why such examples would not be cases of knowledge, because it would be easy for Mary to believe that it is 8:20 am when in fact it is not 8:20 am (it would suffice that she was in a very similar circumstance, but looked at the broken clock one minute before or after 8:20 am); therefore, the safety condition expressed in (SC) is not satisfied.

\section{Counterexamples against (SC)}

However, there is a new and interesting objection to the necessity of this safety condition expressed in (SC) for knowledge inspired by the famous cases of Harry Frankfurt ${ }^{5}$ concerning the problem of the compatibility of determinism and free will (in the relevant sense for moral responsibility).

Schematically, in the original Frankfurt cases, we have the following situation: a subject chooses a certain course of action, but had he opted for a different one, an external factor would have intervened to ensure that he would act in the way he actually did. Thus, in such cases, the subject could not have acted differently. However, in the actual situation, since nothing actually intervened to affect his action, it seems correct to say that the subject was morally responsible for the course of action he adopted. Thus, it seems that a subject's action may be properly due to his agency, as a result of which he is morally responsible, even when he could not have acted otherwise.

Based on this, one can imagine an epistemic case analogous to a Frankfurt-type case to argue against the necessity of the safety condition expressed in (SC), as proposed by Comesaña ${ }^{6}$ and Kelp ${ }^{7}$. For example,

\footnotetext{
${ }^{3}$ Yet there are epistemologists, such as Neta and Rohrbaugh (2004), who object that safety can solve Gettier's problem and argue that there is no such thing as typical Gettier cases. For an answer, see Pritchard (2015). I am grateful to an anonymous reviewer for this note.

${ }^{4}$ For an externalist and reliabilist theory of justification, see Goldman (1979).

${ }^{5}$ Frankfurt (1969).

${ }^{6}$ Comesaña (2013).

${ }^{7}$ Kelp (2009): 27; (2016): 28; (2019): 51.
} 
Suppose that Mary's arch-nemesis, a powerful demon, intends her to form the belief that it's 8:20 am by looking at her kitchen clock when she comes down the stairs. In order to achieve this goal, Mary's arch-nemesis is prepared to set the clock for 8:20 am when she comes down the stairs. However, Mary's arch-nemesis is also lazy. He will act only when Mary does not come down the stairs, by her own accord, at 8:20 am. Suppose Mary comes down the stairs at 8:20 am. Mary's arch-nemesis remains inactive. So, Mary forms the belief that it's 8:20 am, it really is 8:20 am, and her kitchen clock is working reliably as well.

Critics of the safety condition expressed in (SC) claim that Mary knows that it is 8:20 am. After all, we can assume that her belief was the result of properly functioning cognitive faculties, responding adequately and reliably to the evidence. Moreover, the clock was working properly, and Mary's reading of the time was accurate. However, her belief does not satisfy the safety condition expressed in (SC). This is because among the close possible worlds are those worlds where Mary comes down the stairs a few minutes sooner or later. In those worlds the arch-enemy intervenes, and thus Mary forms a false belief that it is 8:20 am. As a result, her belief is not safe and we can therefore have knowledge without the safety condition. I.e., the safety condition expressed in (SC) is not necessary for knowledge, because (SC) is not true.

\section{Response to counterexamples}

Nevertheless, I think that this counterexample, or ones similar to it, do not work. This is because I do not share the intuition that Mary has knowledge in that case. For, after all, given how Mary formed her belief, it was purely a matter of chance that it ended up being a true belief. Had she come down the stairs a minute before or a minute later, she would have formed a false belief. So it was merely by luck that she came to hold a true belief. However, it can be said that Mary's belief has some positive epistemic status, because in that case, given that the arch-nemesis does not intervene, the cognitive success in question is to a significant degree creditable to her cognitive abilities. ${ }^{8}$ But, although her belief is well justified, ${ }^{9}$ it is not a case of knowledge (since her cognitive success is also a matter of "environmental" epistemic luck). But can we have knowledge by luck? Intuitively, if it is veritic epistemic luck as this case seems to be, the answer is no. ${ }^{10}$

After all, Mary attempts to ascertain what time it is in a situation that is not all that different from looking at a stopped clock, for whenever she comes down the stairs the clock will always display "8:20 am". ${ }^{11}$ However, one cannot know the time by looking at a device that ends up being the equivalent of a broken clock, even if a true belief is

\footnotetext{
${ }^{8}$ See Sosa (2007).

${ }^{9}$ Here, we are using the term "justified" in the sense used by Sosa (2007) and other virtue epistemologists, in which a subject $S$ justifiably believes that $p$ if and only if $p$ is produced by an exercise of an ability of $S$ to form true beliefs.

${ }^{10}$ Engel (1992) distinguishes "veritic luck" from "evidential luck" and shows that only "veritic luck" is incompatible with knowledge.

11 This response is inspired by Pritchard (2015).
} 
formed as a result of that. ${ }^{12}$ That is a way of determining the time which is susceptible to a considerable epistemic risk. Thus, the safety condition expressed in (SC) is still necessary for knowledge and that, therefore, epistemic safety is not threatened by Frankfurt type cases. In particular, Kelp's counterexamples are ineffective against (SC).

In response, Kelp ${ }^{13}$ made the following counter-argument: it is a crucial part of the case that the clock is functioning properly and is thus not stopped. So, we cannot appeal to the plausible idea that one cannot acquire knowledge from a stopped clock in order to argue that the epistemic Frankfurt case is not plausible. However, it seems that this counter-argument does not work. Because, for practical purposes, Mary's clock is as good as stopped. This is because whatever the time that Mary looks at her clock, it always shows 8:20 am. In other words, that clock will always show 8:20 am for Mary, there being no way for her to form a different belief based on that clock. So, consulting that clock does not seem like a source of knowledge. ${ }^{14}$

In order to deal with the previous reply, $\mathrm{Kelp}^{15}$ proposes another version of the epistemic Frankfurt case:

Mary's demon nemesis wants Mary to believe either that it is 8:20 or else that it is past 8:20. He has resolved that if Mary comes down before 8:20 he will set the clock to 8:20 and if she comes down at 8:20 or later, he will do nothing. Mary comes down at 8:20, the demon remains inactive, and Mary acquires a true belief by taking a competent reading from a perfectly functioning clock.

According to Kelp ${ }^{16}$, in this case there is knowledge, but without the safety condition expressed in (SC). Moreover, the clock is not stopped (nor is even effectively stopped).

But I think that this reformulation of the epistemic Frankfurt case is not particularly convincing, because until 8:20 that clock is a stopped clock (at least in a pragmatic sense), to all intents and purposes. Moreover, it is not clear that this new version presents a case, at least paradigmatic, of knowledge ${ }^{17}$ - indeed, it can be said that Mary's belief is justified (both internally and externally), but it is doubtful that such a belief of Mary can really be regarded as knowledge (since it could very easily be false, having a strong element of luck in it). After all, it is still by luck that Mary acquired a true belief, because in that epistemic environment she could very easily form a false belief (for example, in

${ }^{12}$ One can object that the counterfactual intervention of the demon is not equivalent to an actual broken clock. But on a pragmatic reading, it looks like a broken clock from Mary's perspective, given that she will not be able to form a difference belief based on this clock. But there is a more central problem: her belief cannot be knowledge because it is subject to significant epistemic risk (as I will argue at the end of this paper).

${ }_{13}$ Kelp (2016): 29; (2019): 106.

${ }^{14}$ One can criticize my argument by claiming that it ultimately boils down to a battle of intuitions, because it seems that no independent criterion is given for assessing the cases. However, at the end of this paper, I seek to offer an independent assessment criterion based on "epistemic risk".

${ }^{15}$ Kelp (2016): 29; (2019): 106.

16 Ibidem.

17 The "paradigmatic cases" are intuitively central, clear, and unequivocal cases of knowledge, where necessary and sufficient conditions are appropriate. 
the situation where she arrives one minute early from 8:20) - and it is a platitude that knowledge excludes luck.

By the way, we can imagine a Gettier case with the same structure: suppose that in the "Fake Barn" $\operatorname{case}^{18}$, Mary is not aware that she is looking precisely at the first real barn in an area where all the previous ones were merely the facades of barns (i.e. structures which, viewed from the road, are indiscernible from real barns, but are false barns) and in which all the following are real ones. It seems that Mary does not know that there is a real barn in front of her. Analogously, in Kelp's case, Mary does not know that it is 8:20. Thus, the new version of the epistemic Frankfurt-type case does not decisively falsify (SC).

This conclusion can be strengthened by considering the intuitive idea that knowledge does not tolerate epistemic risk. ${ }^{19}$ But what is epistemic risk? Starting to characterize risk in general, an event $\mathrm{E}$ is at risk of occurring if only if this $\mathrm{E}$ would occur in a certain proportion of nearby possible worlds. ${ }^{20}$ Applied to the epistemic case, it can be said that a subject's belief is epistemically at risk if only if such a belief would be false by using the same method of belief formation in a certain proportion of nearby possible worlds. But how broad should such a proportion be? Although this response involves vagueness, we would not say that a belief is epistemically at risk if the proportion of possible worlds in which the belief would be false were small. Thus, following Pritchard, ${ }^{21}$ it is plausible to define epistemic risk as follows:

A belief $p$ of $S$ is at risk of being false if only if $p$ is false in at least half of the nearby possible worlds where $S$ believes $\mathrm{p}$ (on the same basis as in the actual world in question).

With this characterization it can be said that the fake barns case, as described above, involves significant epistemic risk ${ }^{22}$ and if so, then also epistemic Frankfurt-type cases involve significant epistemic risk since the main structure of these two cases is similar. Thus, in such cases there is no knowledge. Kelp ${ }^{23}$ attempts to give some reasons for believing that these two cases are not structurally analogous, because "in fake barn cases the relevant error possibilities are realised in the environment in a way in which they aren't in Frankfurt cases". While this may be true, it can be said that the cases are structurally analogous with respect to epistemic risk (modeled in terms of possible worlds) and that is enough to rule out the objection to the safety condition. ${ }^{24}$

\footnotetext{
18 See Goldman (1976).

${ }^{19}$ See Pritchard (2016).

${ }^{20}$ Possible worlds are understood by Pritchard (2005): 128: "as ordered in terms of their similarity to the actual world (i.e., so that 'distant' possible worlds are very unlike the actual world, whilst 'nearby' possible worlds are very alike the actual world)".

${ }_{21}$ Pritchard $(2005 ; 2016)$.

${ }^{22}$ This is because in at least half of the nearby possible worlds, Mary forms a false belief.

${ }^{23}$ Kelp (2019): 52.

${ }^{24}$ Acknowledgements: I am grateful to the anonymous referees for their comments in an earlier version of this article. Thanks to Ricardo Santos, Luis Veríssimo, Diogo Santos, Ricardo Miguel for helpful comments and discussion on an earlier version of this paper. Any errors or omissions are my responsibility. Work for this paper was supported by the post-doctoral project CEECIND/01066/2017 of the Portuguese Foundation for Science and Technology.
} 


\section{References}

Comesaña J. (2013), "Safety and Epistemic Frankfurt Cases," [in:] Virtuous Thoughts: The Philosophy of Ernest Sosa, J. Turri (ed.), Springer, Dordrecht: 165-178.

Engel M. (1992), "Is Epistemic Luck Compatible with Knowledge?," Southern Journal of Philosophy 30 (2): 59-75.

Frankfurt H. (1969), “Alternate Possibilities and Moral Responsibility," Journal of Philosophy 66 (23): 829-839.

Goldman A. (1976), "Discrimination and Perceptual Knowledge," Journal of Philosophy 73 (20): 771-791.

Goldman A. (1979), “What Is Justified Belief?,” [in:] Justification and Knowledge, G.S. Pappas (ed.), D. Reidel Publishing Company, Dordrecht: 1-23.

Kelp C. (2009), "Knowledge and Safety," Journal of Philosophical Research 34: 21-31.

Kelp C. (2016), "Epistemic Frankfurt Cases Revisited," American Philosophical Quarterly, 53 (1): 27-37.

Kelp C. (2019), Good Thinking: A Knowledge First Virtue Epistemology, Routledge, New York.

Neta R., Rohrbaugh G. (2004), "Luminosity and the Safety of Knowledge," Pacific Philosophical Quarterly 85 (4): 396-406.

Pritchard D. (2005), Epistemic Luck, Oxford University Press, Oxford.

Pritchard D. (2015), "Anti-Luck Epistemology and the Gettier Problem," Philosophical Studies 172 (1): 93-111.

Pritchard D. (2016), "Epistemic Risk," Journal of Philosophy 113 (11): 550-571.

Sosa E. (2007), A Virtue Epistemology: Apt Belief and Reflective Knowledge, Volume I, Oxford University Press, Oxford. 